\title{
A high-performance liquid chromatographic (HPLC) method for the determination of amlodipine drug in dosage form using I,2-naphthoquine-4-sulfonate (NQS)
}

\begin{abstract}
A rapid, simple and sensitive high-performance liquid chromatographic (HPLC) method for determination of Amlodipine (AML) using sodium 1,2-naphthoquinone-4-sulfonate (NQS) has been developed. The method is based on the formation of a brown color product from the reaction between AML and NQS. The nucleophilic substitution reaction proceeds quantitatively at $\mathrm{pH} 13$ buffer solution with absorption maximum at $465 \mathrm{~nm}$. $\mathrm{A} \mathrm{C}_{18}$ column ODS $(250 \mathrm{~mm} \times 4.6 \mathrm{~mm}), 5 \mu \mathrm{m}$ and a mobile phase of combination is potassium dihydrogen orthophosphate $(0.05 \mathrm{M})$ in water: acetonitrile $(45: 55 \% \mathrm{v} / \mathrm{v})$ were used for separation and quantification. Analyses were run at a flow-rate of $1.5 \mathrm{~mL} / \mathrm{min}$ and at $40{ }^{\circ} \mathrm{C}$ temperature. The injection volume was $20 \mu \mathrm{L}$ and the photodiode array detector was set at $465 \mathrm{~nm}$. Under these conditions Amlodipine-NQS eluted at $3.12 \mathrm{~min}$. Total run time was shorter than 5 $\mathrm{min}$. The developed method was validated according to the literature and found to be linear within the range $2-30 \mu \mathrm{g} / \mathrm{mL}$, describes by the regression equation $\mathrm{y}=207,082 \mathrm{x}+1,481.71$ with a regression coefficient 0.999 . The limit of detection and quantity are $0.01 \mu \mathrm{g} / \mathrm{mL}$ and $0.04 \mu \mathrm{g} / \mathrm{mL}$ respectively. This method is simple and can be applied for the determination of $\mathrm{AML}$ in pharmaceutical formulation in quality control laboratories.
\end{abstract}

Keywords: Amlodipine besylate; High performance liquid chromatography; Method development; Sodium 1,2-naphthoquine-4sulfonate
Volume 6 Issue I - 2017

\section{Rami Ali Mohammed Osman, Abdalla Ahmed Elbashir \\ Department of Chemistry, Faculty of science, University of Khartoum, Sudan}

Correspondence: Abdalla Ahmed Elbashir, Department of Chemistry, Faculty of science, University of Khartoum, Sudan, Email aaelbashir@uofk.edu

Received: August 01, 2017 | Published: August 29, 2017
Abbreviations: HPLC, high-performance liquid chromatographic; AML, amlodipine; NQS, 1,2-naphthoquinone4-sulfonate; TLC, thin layer chromatography; LC-MS, liquid chromatography mass spectrometry

\section{Introduction}

Amlodipine Besylate (AML), chemically is 3-ethyl 5-methyl (4RS)-2-[(2-aminoethoxy) methyl]-4-(2chlorophenyl)-6-methyl-1,4dihydropyridine-3,5-dicarboxylate benzene sulphonate (Figure 1). It belongs to the class of calcium channel blocker, AML is a long-acting calcium channel blocker (dihydropyridine derivative) used as an antihypertensive and in the treatment of angina. ${ }^{1}$

Literature review showed different analytical methods for the analysis of amlodipine in pharmaceutical preparations or biological fluids either as a single drug or in combination with other drugs. Those analytical methods include: spectrophotometric methods with or without derivatization..$^{2-7}$ The derivative spectroscopy has also been applied for the determination of amlodipine and its photodegradant compound. ${ }^{8}$ Chromatographic methods have been used widely for the analysis of AML, including thin layer chromatography (TLC) methods $^{9-12}$ and HPLC methods. ${ }^{13,14}$ Capillary electrophoresis methods were also used for the analysis of AML in its formulations and biological fluids. ${ }^{15,16}$ AML was also determined using liquid chromatography mass spectrometry (LC-MS). ${ }^{17,18}$

1, 2-naphthoquinone-4-sulphonate (NQS) has been used as a chromogenic reagent for the colorimetric determination of many pharmaceutical amines. ${ }^{19-21}$ The applications of NQS for determination of pharmaceutical bearing amine group have been reviewed by Elbashir et al. ${ }^{22-27}$ However, the reaction of NQS with AML has to the best of our knowledge, not been investigated. Therefore the present study is devoted to investigate the optimum reaction conditions of NQS with AML using spectrophotometry and application for the development of a simple and rapid HPLC method for the determination of AML in pharmaceutical dosage forms.

\section{Materials and methods}

\section{Materials}

Amlodipine Besylate working standards was donated from Azal pharmaceutical industries company Ltd, (Khartoum, Sudan). Acetonitrile HPLC grade, Methanol HPLC grade, Potassium dihydrogen orthophosphate AR and sodium hydroxide were purchased from scharlau chemical (spain). High purity deionised water was obtained from Azal pharmaceutical (Khartoum, Sudan) purification system. Sodium 1, 2-naphthoquinone-4sulphonate (NQS) (Sigma Aldrich Chemical Co, St. Louis, USA).

\section{Methods}

Instrumentation: Chromatographic separation was performed with Shimadzu high performance liquid chromatography having $\mathrm{C} 18$, ODS $(250 \mathrm{~mm} \times 4.6 \mathrm{~mm}), 5 \mu \mathrm{m}$ analytical column with photodiode array detector provided by Auto sampler and the Chromatographic data were recorded by LC Solution software. Absorbance was carried out by using UV-visible spectrophotometer model Shimadzu 1800 with quartz cells of $1 \mathrm{~cm}$ optical path length, $\mathrm{pH}$ meter was used for $\mathrm{pH}$ measurements, analytical balance and ultrasonic bath.

Chromatographic conditions: For HPLC a number of preliminary trials were conducted with combinations of different organic solvents, compositions, and flow rate to check the retention time, shape, 
resolution, and other chromatographic parameters. Among all tried experiments, the mobile phase combination of potassium dihydrogen orthophosphate $(0.05 \mathrm{M})$ in water: acetonitrile $(45: 55 \% \mathrm{v} / \mathrm{v})$ was found to be more suitable. The solution was degassed in an ultrasonic water bath for 5 minutes and filtered through $0.45 \mu \mathrm{m}$ nylon filter. The instrumental settings flow rate of $1.5 \mathrm{~mL} / \mathrm{min}$; the column temperature is $40^{\circ} \mathrm{C}$, and detector wavelength is $465 \mathrm{~nm}$ found to be most suitable. Best resolution and sensitivity of the method were obtained for NQS and AML. Typical chromatogram with optimized condition gives sharp and symmetric peak with retention time of $3.132 \mathrm{~min}$

\section{Preparation of standard and sample solutions}

Standard solution of AML (200 $\mu \mathrm{g} / \mathrm{mL})$ : An accurately $20 \mathrm{mg}$ of AML standard was dissolved in a mixture of equal volume of methanol and distilled water, transferred into $100 \mathrm{~mL}$ volumetric flask, diluted to the mark with same solvent and mixed well.

Sodium 1, 2-naphthoquinone-4-sulfonic solution $(0.5 \%$ w/v): (NQS) $0.5 \%(\mathrm{w} / \mathrm{v})$ was prepared by dissolving $0.5 \mathrm{~g}$ in mixture of equal volume of methanol and distilled water, transferred into a $100 \mathrm{~mL}$ volumetric flask and diluted to the mark with same solvent and mixed well. The solution was freshly prepared and protected from light during use.

Buffer solutions: Buffer solution of $\mathrm{pH} 13.0$ was prepared by mix solution of $0.2 \mathrm{M}$ potassium dihydrogen phosphate and $0.2 \mathrm{M}$ sodium hydroxide adjusted to $\mathrm{pH} 13.0$ with $0.2 \mathrm{M}$ sodium hydroxide.

Sample solution: Preparation of Amlodipine tablets by an accurately weighed $700 \mathrm{mg}$ of amlodipine tablet equivalent to $20 \mathrm{mg}$ of Amlodipine, dissolved by sonication in a mixture of equal volume of methanol and distilled water into a $100 \mathrm{~mL}$ volumetric flask, diluted to the mark with the same solvent $(200 \mu \mathrm{g} / \mathrm{mL})$.

\section{General recommended procedure}

A $1.0 \mathrm{~mL}$ of $200 \mu \mathrm{g} / \mathrm{mL}$ of Amlodipine was transferred into $10 \mathrm{~mL}$ volumetric flask; $1.5 \mathrm{~mL}$ of $0.5 \%$ (NQS) was added and followed by $1.5 \mathrm{~mL}$ buffer solution $\mathrm{pH} 13.0$. The reaction was completed to volume with mixture of equal volume of methanol and distilled water, After 5 min, a suitable volume of solution was sampled and filtered through $0.45 \mu \mathrm{m}$ membrane filter paper. The solution was determined by HPLC conditions developed herein.

\section{Determination of the stoichiometric ratio of the reaction (Job's method)}

The Job's method (Oliner \& Boyd 1964) of continuous variation was employed. Equimolar (5x10-3 M) aqueous solutions of AML and NQS were prepared. A series of $10 \mathrm{~mL}$ portions of stock solutions of AML and NQS were made up comprising different complementary proportions $(0: 10,1: 9,2: 8,3: 7,4: 6,5: 5,6: 4,7: 3,8: 2,9: 1,10: 0)$. The solution was further treated as described under the general recommended procedure.

\section{Results and discussion}

\section{Absorption spectra}

The absorption spectrum of AML was recorded against mixture of methanol and water (50:50) (Figure 2); it was found that AML exhibits a maximum absorption peak $\left(\lambda_{\max }\right)$ at $238 \mathrm{~nm}$. Because of highly orange shifted $\lambda_{\max }$ of AML, its determination in the dosage form based on the direct measurement of its absorption for ultraviolet is susceptible to potential interferences from the common excipients.
Therefore, derivatization of AML red-shifted light-absorbing derivative was necessary. The reaction between AML and NQS was performed, and the absorption spectrum of the product was recorded against reagent blank (Figure 2). It was found that the product is brown colored exhibiting $\lambda_{\max }$ at $465 \mathrm{~nm}$, and the $\lambda_{\max }$ of NQS was 361 $\mathrm{nm}$. The $\lambda_{\text {max }}$ of AML-NQS derivative was red-shifted, eliminating any potential interference. Therefore, the measurements were carried out at $465 \mathrm{~nm}$.

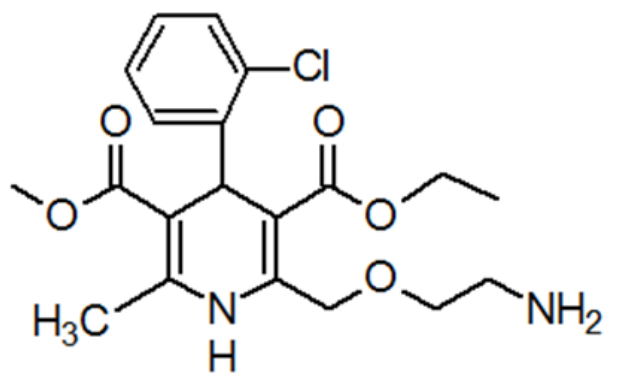

Figure I Chemical structure of Amlodipine.

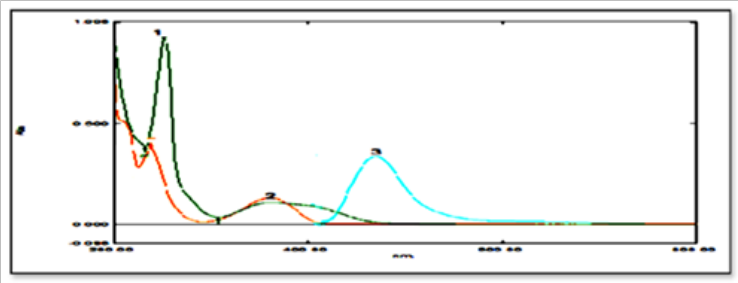

Figure 2 Absorption spectra of (I) NQS (2) Amlodipine (3) Amlodipine NQS derivative.

\section{Stoichiometry of derivatization reaction}

Under the optimum conditions the stoichiometry of the reaction between AML with NQS was investigated by Job's method and was found to be 1:1, While AML molecule contain primary and secondary amino group. Based on this ratio, the reaction pathway was postulated to be proceeded as shown in Scheme 1.

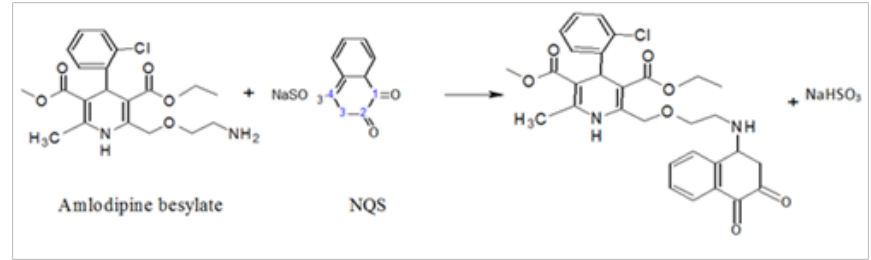

Scheme I Reaction pathway of AML with NQS.

\section{Optimization of derivatization reaction and spectrophotometric procedure}

Effect of pH: The effect of $\mathrm{pH}$ on the reaction of AML with NQS was investigated. By varying the $\mathrm{pH}$ from 6.0 to 13.5 , the influence of $\mathrm{pH}$ on the absorbance of AML-NQS product is shown in Figure 3. The results revealed that the absorbance's at $\mathrm{pH}$ less than 6-8 were close to 0 , indicating that underthis $\mathrm{pH}$ range, AML has difficulty to react with NQS. At $\mathrm{pH}$ more than8.0, the absorbance increased rapidly with the increase in the $\mathrm{pH}$, as the amino group of AML turns into the free$\mathrm{NH}$, facilitating the nucleophilic substitution reaction. The maximum absorption values were attained in the range of $\mathrm{pH}$ at 13.0. At $\mathrm{pH}$ 
more than 13.5 the absorbance of solution obviously decreased. This was attributed probably to the increase in the amount of hydroxide ion that holds back the condensation reaction between AML and NQS. In order to keep the high sensibility for determination of amlodipine, the experiment was carried out at $\mathrm{pH}$ 13.0.

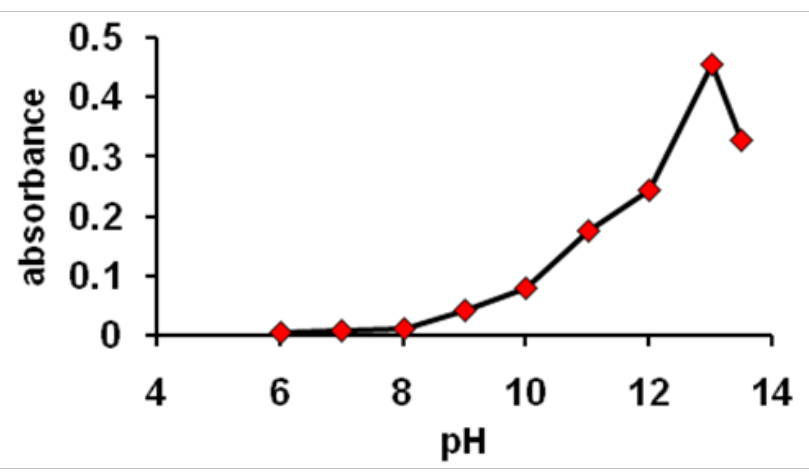

Figure 3 Effect of $\mathrm{pH}$ on absorbance of product AML with NQS, AML $(200 \mu \mathrm{g} / \mathrm{mL})$ : $1.0 \mathrm{~mL}$; buffer solution: I.0mL; NQS $(0.5 \%, \mathrm{w} / \mathrm{v})$ : $1.0 \mathrm{~mL}$; at room temperature; reaction time: $5 \mathrm{~min}$.

Effect of (NQS) concentration: The studying of NQS concentrations revealed that the reaction was dependent on NQS reagent. The absorbance of the reaction solution increased as the NQS concentration increased, and the highest absorption intensity was attained at NQS concentration of $0.5 \%(\mathrm{w} / \mathrm{v})$ Figure 4. Higher NQS concentrations up to $0.8 \%$ had no effect on the absorption values. Further experiments were carried out using $0.5 \%(\mathrm{w} / \mathrm{v})$.

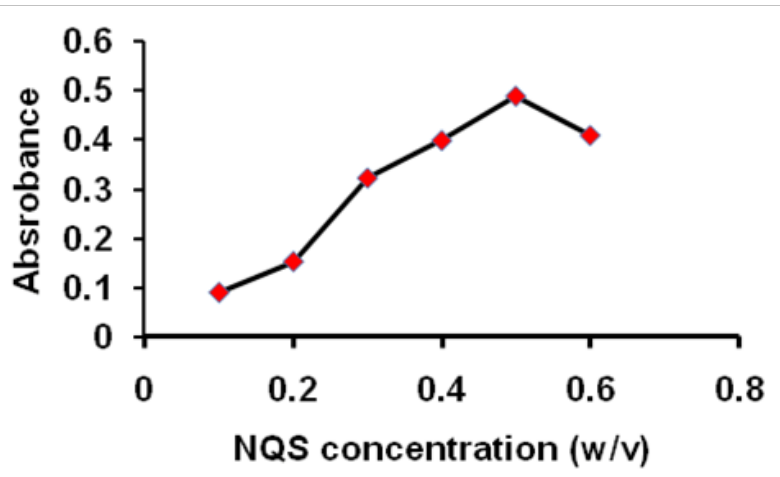

Figure 4 Effect of NQS concentrations on the reaction of AMLwith NQS. AML $(200 \mu \mathrm{g} / \mathrm{mL})$ : I.0mL; NQS: I.0mL; buffer solution ( $\mathrm{pH}$ I3): I.0mL; at room temperature; reaction time: $5 \mathrm{~min}$

Effect of reaction time: Keeping the experimental conditions unchanged, the absorbance of the solution of AML-NQS complex was measured after standing for various time periods, Figure 5. The results show that AML reacts immediately with NQS at room temperature; $5 \mathrm{~min}$ is selected as the optimum condition.

Effect of amount of the buffer: Keeping $\mathrm{pH}$ at 13.0, the effect of amount of buffer solution on the absorbance of reaction product was also studied. It shows that the absorbance of the reaction product enhances rapidly with the rise of amount of buffer solution, and becomes maximal when the amount of buffer solution is $1.5 \mathrm{~mL}$. Therefore, the amount of $1.5 \mathrm{~mL}$ buffer solution was selected to ensure the highest absorbance.

\section{Validation of the methods}

Methods Validation: Establishing documented evidence that provides a high degree of assurance that a specific method, and the ancillary instruments included in the method, will consistently yield results that accurately reflect the quality characteristics of the product tested. The most widely applied typical validation characteristics for various types of tests are accuracy, precision (repeatability and intermediate precision), specificity, detection limit, quantitation limit, linearity, range, and robustness.

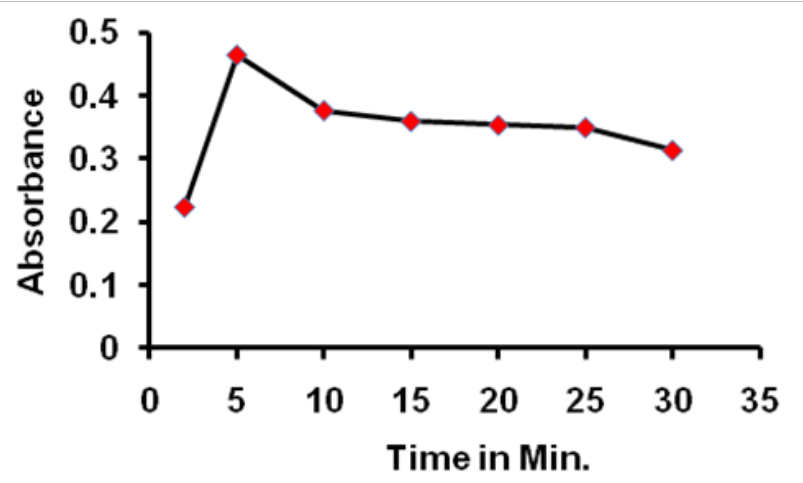

Figure 5 Effect of standing time on the reaction of AMLwith NQS. AML $(200 \mu \mathrm{g} / \mathrm{mL})$ : I.0mL; buffer solution $(\mathrm{pH}$ I3): I.0mL; NQS $(0.5 \%, \mathrm{w} / \mathrm{v}): 1.0 \mathrm{~mL}$; at room temperature.

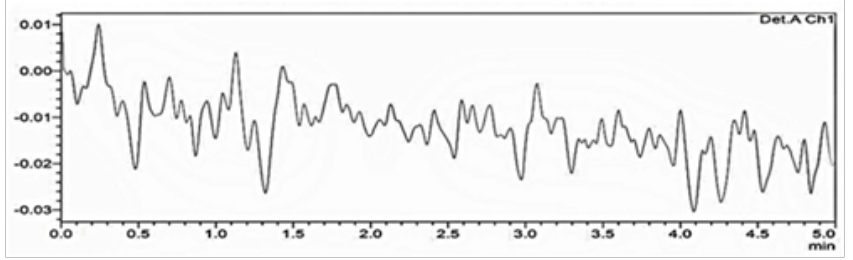

Figure 6 Chromatographic peak of placeboshow no peak interference $(465 \mathrm{~nm})$.

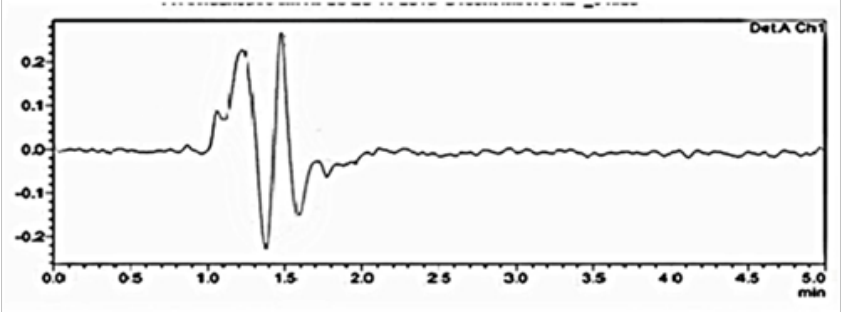

Figure 7 Chromatographic peak of mobile phase show no peak interference $(465 \mathrm{~nm})$.

\section{Specificity}

The specificity of the assay method was investigated by the injection of the extracted placebo and mobile phase to demonstrate the absence of interference with the elution of analyte. The injected of placebo and mobile phase found that no of interference between AML, NQS and mobile phase (Figure $6 \& 7$ ). Also the injection of AML and NQS have shown no interference and the method should be selective (Figure 8 \& 9).

\section{Linearity}

The linearity was evaluated by linear regression analysis determined by its reaction with NQS was constructed by plotting area as a

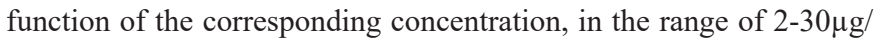
$\mathrm{mL}$, which was calculated by the least square regression method to calculate the calibration equation and the correlation coefficient. The calibration curves were constructed by plotting concentration versus peak area Figure 10, using linear regression analysis. The regression 
equation for the results was $y=207,082 x+1,481.71\left(r^{2}=0.999\right)$, where $\mathrm{y}$ is the area at $465 \mathrm{~nm}$, $\mathrm{x}$ is the concentration of amlodipine in $\mu \mathrm{g} / \mathrm{ml}$ in the range of $2-30 \mu \mathrm{g} / \mathrm{mL}$, and $\mathrm{r}$ is correlation coefficient (Table 1). The limit of detection (LOD) and limit of quantification (LOQ) were determined according to the following formula $\mathrm{LOD}=3.3 \times \mathrm{SDa} / \mathrm{b}$, and $\mathrm{LOQ}=10 \times \mathrm{SDa} / \mathrm{b}, \mathrm{SDa}$ is the standard deviation of the blank, $\mathrm{b}$ is the slope under the ICH guidelines. The LOD and LOQ were found to be 0.01 and $0.04 \mu \mathrm{g} / \mathrm{mL}$, respectively Table 1 .

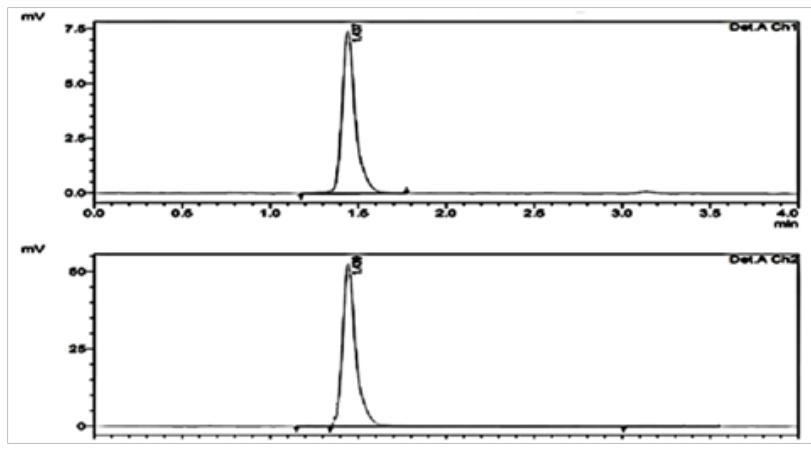

Figure 8 Chromatographic peak of NQS in ChI (465 nm) and Ch2 (27I) show the peak in same retention time.

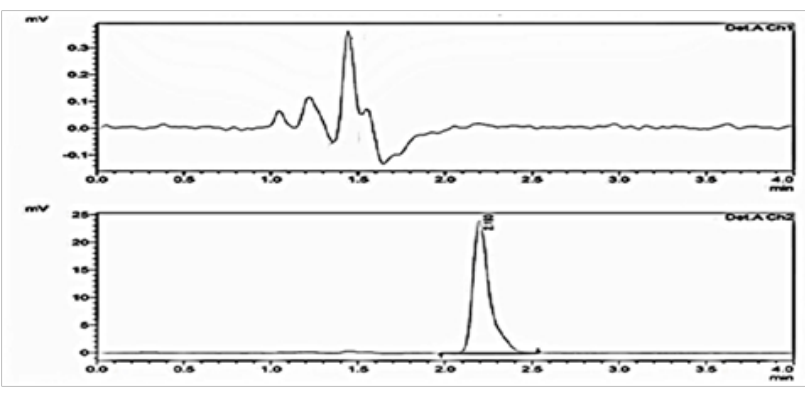

Figure 9 Chromatographic peak of amlodipine Besylate in ChI (465nm) no peak due to amlodipine and Ch2 (27I) the Amlodipine eluted.

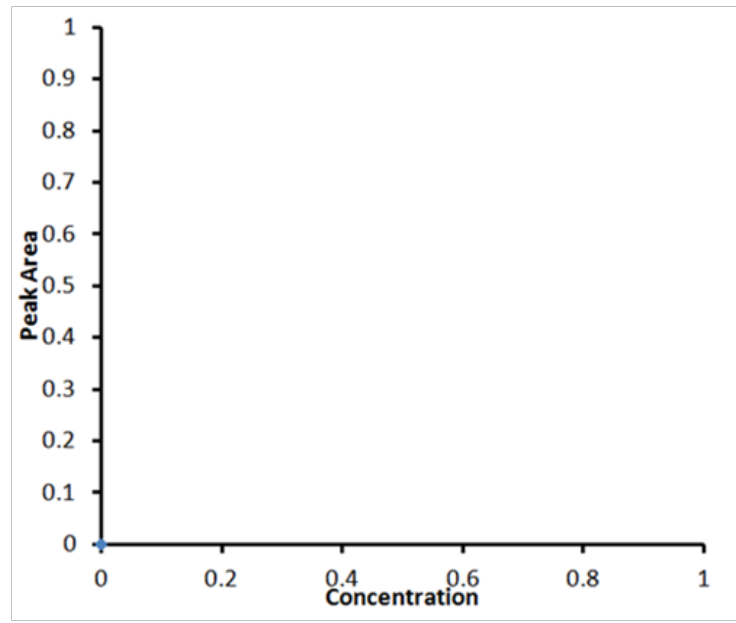

Figure 10 Calibration curve AML

\section{Accuracy}

Accuracy expresses the closeness of agreement between the conventional true value or an accepted reference value and the value found. The accuracy of the proposed method was carried out by applying 3 different concentrations 16,20 , and $24 \mu \mathrm{g} / \mathrm{mL}$ of AML drug within linear range calculated as the percentage of the drug recovered from the samples, Table 2 .

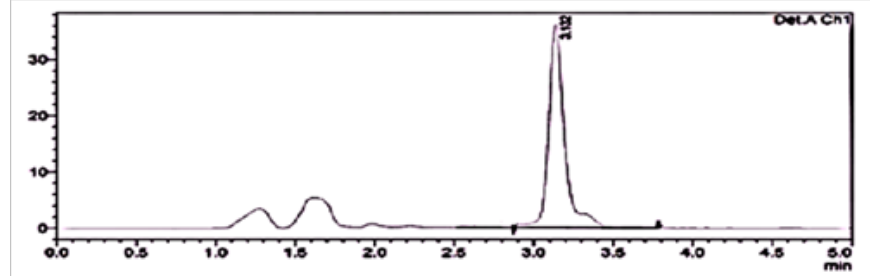

Figure I I Chromatographic peak of amlodipine Besylate - NQS (465nm).

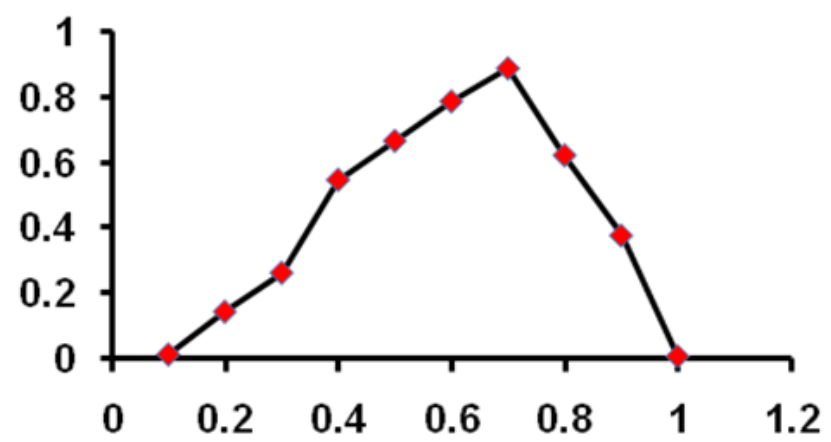

Figure 12 The continuous variation plots for the stoichiometry of the reaction of $A M L$ with NQS.

\section{Robustness}

The robustness is defined as a measure of its capacity to remain unaffected by small but deliberate variations in experimental parameters, providing an indication of the analytical method's suitability and reliability during normal use. In these experiments, one parameter was changed whereas the others were kept unchanged, and the retention time of peak was recorded each time. It was found that small variation in the method variables did not significantly affect the procedures, Table 3 .

\section{Application of the proposed method to analysis of AML dosage form}

AML tablets were subjected to the analysis by the proposed as well as with the official HPLC method (United States pharmacopeia) and the obtained results were statistically compared with each other. The label claim percentage was 99.63 and 99.75 for amlozal batch No 6206 (Table 4). This indicated similar accuracy and precision in the analysis of AML in tablets. The proposed method has the advantage of being virtually free from interferences by excipients as shown in Figure 11.

\section{Reaction mechanism}

Derivatization of AML was attempted in the present study for the development of HPLC method for its determination. The present method is based on the reaction between the NQS and AML molecules. The NQS reagent reacts with AML at the free NH group. The reagent blank has negligible absorbance in the range used for detection of the AML. Similarly, amino group of AML, taking on nucleophilicity due lone electron pair of nitrogen atom, trend to attack on the electron-deficient center in NQS, namely no.4 carbon atom (3,4- $\mathrm{C}=\mathrm{C}$ carbon bond conjugate with $2-\mathrm{C}=\mathrm{O}$, as a result $4-\mathrm{C}$ of NQS becomes electron lacking center). At the same time, it has been proved that the composition of product I is 1:1 of AML and NQS (Figure 12). So it is concluded that amino group of AML react with 4-sodium sulphonate of NQS molecule respectively, to form brown N-alkylamino naphthoquinone. The reaction equation is shown in Scheme 1. 
Table I Parameters for the performance of the proposed method

\begin{tabular}{ll}
\hline Parameter & Value \\
\hline Measurement wavelength $(\mathrm{nm})$ & $465 \mathrm{~nm}$ \\
Linear range $(\mu \mathrm{g} / \mathrm{mL})$ & $2-30 \mu \mathrm{g} / \mathrm{mL}$ \\
Standard deviation of the Blank Slope & 1035 \\
Intercept & 1481.714286 \\
Slope & 207081.964286 \\
Correlation coefficient $(\mathrm{r})$ & 0.999 \\
Limit of detection, LOD $(\mu \mathrm{g} / \mathrm{mL})$ & 0.02 \\
Limit of quant., LOQ $(\mu \mathrm{g} / \mathrm{mL})$ & 0.05 \\
\hline
\end{tabular}

Table 2 Recovery studies for the determination of amlodipine, by the proposed method

\begin{tabular}{lllll}
\hline Sample No & Sample Content $(\boldsymbol{\mu g} / \mathbf{m L})$ & Amount Amlodipine & Amount Found & Recovery \\
\hline $\mathrm{I}$ & 16 & 16 & 15.98 & 99.875 \\
2 & 20 & 20 & 19.89 & 99.45 \\
3 & 24 & 24 & 23.86
\end{tabular}

Table 3 Influence of small variation in the assay condition on the analytical performance of the proposed HPLC method for determination of AML using NQS reagent

\begin{tabular}{|c|c|c|c|c|c|c|c|}
\hline Change in & Before Change & Flow Rate & Flow Rate & Mobile Phase & Mobile Phase & & \\
\hline Parameter & & $1.4 \mathrm{ml} / \mathrm{min}$ & $1.6 \mathrm{~mL} / \mathrm{min}$ & + I0\% Acetonitrile & - I0 \% Acetonitrile & $-5 n m$ & $+5 \mathrm{~nm}$ \\
\hline Retention Time I & 3.13 & 3.347 & 3.002 & 2.888 & 3.675 & 3.12 & 3.13 \\
\hline Retention Time 2 & 3.11 & 3.348 & 3.011 & 2.886 & 3.678 & 3.12 & 3.13 \\
\hline Retention Time 3 & 3.12 & 3.346 & 3.012 & 2.889 & 3.677 & 3.13 & 3.13 \\
\hline Avg for Retention Time & 3.12 & 3.347 & 3.008 & 2.888 & 3.677 & 3.12 & 3.13 \\
\hline RSD\% & 0.321 & 0.030 & 0.183 & 0.053 & 0.042 & 0.067 & 0.49 \\
\hline Tailing Factor I & 1.231 & 1.222 & 1.239 & 1.181 & 1.269 & 1.23 & 1.22 \\
\hline Tailing Factor 2 & 1.242 & 1.225 & $1.24 \mid$ & $\mathrm{I} .183$ & 1.27 & 1.22 & 1.23 \\
\hline Tailing Factor 3 & $1.24 \mid$ & 1.227 & 1.243 & 1.183 & 1.265 & 1.22 & 1.21 \\
\hline Avg for Tailing Factor & 1.238 & I.22467 & I.24I & I.I8233 & 1.268 & 1.22 & 1.22 \\
\hline RSD $\%$ & 0.491 & 0.205 & 0.161 & 0.098 & 0.209 & 0.125 & 0.592 \\
\hline
\end{tabular}

Table 4 Analysis of Amlodipine containing dosage forms by the proposed and Official HPLC methods (United States Pharmacopoeia)

\begin{tabular}{llll}
\hline Dosage form & $\begin{array}{l}\text { Recovery \% +RSD } \\
\text { Official Method }\end{array}$ & Proposed Method & Agreement Between Two Methods \\
\hline Amlozal batch \# 6206 & 99.8 & 99.6 & 100.2 \\
Amlozal batch \# 6206 & 99.45 & 99.7 & 99.55 \\
Average \% & 99.63 & 99.75 & 99.9 \\
\hline
\end{tabular}

\section{Conclusion}

The present paper described the evaluation of NQS as analytical reagents in the development of simple, sensitive, and accurate HPLC methods, for the determination of AML in pharmaceutical formulation. The proposed method is simple, reliable, specific, accurate, reproducible, and highly sensitive, for the determination of AML in commercially available dosage forms. The procedure presented here does not need necessitate any expensive apparatus; therefore the proposed method can be used advantageously as a routine method for the determination of AML in quality control and industry, our method may be applied to the determination of other secondary amine derivatives as well.

\section{Acknowledgments}

None.

\section{Conflicts of Interset}

None.

\section{References}

1. Aryal S, Skalko-Basnet N. Stability of amlodipine besylate and atenolol in multicomponent tablets of mono-layer and bi-layer types. Acta pharm. 2015;58(3):299-308.

2. Belal SF, Haggag RS, Shaalan RAA. The Use of an Aromatic Substitution Reaction in the Spectrophotometric Determination of Selected Amino or Thiol Containing Drugs. J Food Drug Anal. 2008;16(1):26-33.

3. Bernard S, Mathew M, Senthilkumar KL. Spectrophotometric method of estimation of Amlodipine besylate using hydrotropic solubilization. $J$ Appl Pharm Sci. 2011;1(9):177-180.

4. Derayea SM, Askal HF, Abdel-Megeed OH, et al. Spectrophotometric determination of amlodipine and nicardipine in pharmaceutical formulations via binary complex formation with eosin Y. J Appl Pharm Sci. 2012;2(6):84-89.

5. Mishra P, Shah K, Gupta A. Spectrophotometric methods for simultaneous estimation of nebivolol hydrochloride and amlodipine besylate in tablets. Int J Pharm Pharm Sci. 2009;1(2):55-61. 
6. Patil PR, Rakesh SU, Dhabale P, et al. Simultaneous UV Spectrophotometric Method for Estimation of Losartan Potassium and AmlodipineBesylate in Tablet Dosage Form. Asian Journal of Research in Chemistry. 2009;2(1):183-187.

7. Rahman N, Nasrul Hoda M. Validated spectrophotometric methods for the determination of amlodipine besylate in drug formulations using 2,3-dichloro 5,6-dicyano1,4-benzoquinone and ascorbic acid. J Pharm Biomed Anal. 2003;31(2):381-392.

8. Ragno G, Garofalo A, Vetuschi C. Photodegradation monitoring of amlodipine by derivative spectrophotometry. $J$ Pharm Biomed Anal. 2002;27(1-2):19-24.

9. Argekar A, Powar S. Simultaneous determination of atenolol and amlodipine in tablets by highperformance thin-layer chromatography. $J$ Pharm Biomed Anal. 2000;21(6):1137-1142.

10. Dhaneshwar SR, Patre NG, Mahadik MV. Validated TLC Method for Simultaneous Quantitation of Amlodipine Besylate and Valsartan in Bulk Drug and Formulation. Chromatographia. 2009;69(1):157-161.

11. Meyyanathan S, Suresh B. HPTLC method for the simultaneous determination of amlodipine and benazepril in their formulations. $J$ Chromatogr Sci. 2005;43(2):73-75.

12. Patel DB. Simultaneous Estimation of Amlodipine Besylate and Indapamide in Pharmaceutical Formulation by Thin-Layer Chromatographic Densitometric method. Novel Science-IJPS. 2002;1(2).

13. Chitlange S, Bagri K, Sakarkar D. Stability indicating RPHPLC method for simultaneous estimation of valsartan and amlodipine in capsule formulation. Asian J Res Chem. 2008;1:15-18.

14. El-Gizawy SM, Abdelmageed OH, Omar MA, et al. Development and Validation of HPLC Method for Simultaneous Determination of Amlodipine, Valsartan, Hydrochlorothiazide in Dosage Form and Spiked Human Plasma. AJAC. 2012;3(6):422-430.

15. Alnajjar AO. Validation of a Capillary Electrophoresis Method for the Simultaneous Determination of Amlodipine Besylate and Valsartan in Pharmaceuticals and Human Plasm. J AOAC Int. 2001;94(2):498-502.

16. Mikus P, Marakova K, Marak J, et al. Pharmacokinetic Study of Amlodipine in Human Urine Using On-Line Coupled IsotachophoresisCapillary Zone Electrophoresis with Diode Array Detection. Current Pharmaceutical Analysis. 2009;5(2):171-178.
17. Bhatt J, Singh S, Subbaiah G, et al. A rapid and sensitive liquid chromatography - tandem mass spectrometry (LC-MS/MS) method for the estimation of amlodipine in human plasma. Biomed Chromatogr. 2007;21(2): 69-175.

18. Karra V, Pilli N, Inamadugu J, et al. Simultaneous determination of losartan, losartan acid and amlodipine in human plasma by LC-MS/MS and its application to a human pharmacokinetic study. Pharm Methods. 2002;3(1):18-25.

19. Ashraf MM, Nasr KY, Ibrahim DA, et al. Selective Spectrophotometric and Spectrofluorometric Methods for the Determination of Amantadine Hydrochloride in Capsules and Plasma via Derivatization with 1 , 2-Naphthoquinone-4-sulphonate. Int J Anal Chem. 2009;10:1155-1162.

20. Li QM, Li J, Yang ZJ. Study of the sensitization of tetradecyl benzyl dimethyl ammonium chloride for spectrophotometric determination of dopamine hydrochloride using sodium 1,2-naphthoquinone-4-sulfonate as the chemical derivative chromogenic reagent. Anal Chim Acta. 2007;583(1):147-152

21. Hasani M, Yaghoubi L, Abdollahi H. A kinetic spectrophotometric method for simultaneous determination of glycine and lysine by artificial neural networks. Anal Biochem. 2007;365(1):74-81.

22. Ebraheem SAM, Elbashir AA, Abou-Enein HY. Spectrophotometric methods for the determination of gemifloxacin in pharmaceutical formulations. Acta Pharma Sinica. 2011;4(2):248-253.

23. Ahmed SMA, Elbashir AA, Aboul-Enein HY. New spectrophotometric Method for determination of cephalosporins in pharmaceutical formulations. Arabian Journal of Chemistry. 2015;8(2):233-239.

24. Elbashir AA, Ahmed SMA, Aboul-Enein HY. New spectrofluorimetric method for determination of cephalosporins in pharmaceutical formulations. J Fluoresc. 2012;22(3):857-864.

25. Elbashir AA, Elwagee AHE. Spectrophotometric determination of pyrimethamine (PYM) in pharmaceutical formulation using 1,2-naphthoquinone4-sulfonate (NQS). Journal of the Association of Arab Universities for Basic and Applied Sciences. 2012;11:32-36.

26. Elbashir AA, Abir AA, Shazalia MAA, et al. 1, 2-naphthoquinone4-sulphonic acid sodium salt (NQS) as an analytical reagent for the determination of pharmaceutical amine by spectrophotometry. Journal of Spectroscopy Review. 2012;47(3):219-232.

27. Job P. Advanced physicochemical Experiments. (2nd edn), Oliner and Boyd, Edinburgh, USA, 1963. p. 54. 